\title{
O DIREITO À SAUDE EM TEMPOS DE PANDEMIA E O ATIVISMO JUDICIAL
}

\author{
THE RIGHT TO HEALTH IN TIMES OF PANDEMICS AND JUDICIAL ACTIVISM
}

\author{
Maynara Cavalcante Trajano ${ }^{1}$ \\ Alexandre Victor Murata Costa ${ }^{2}$
}

RESUMO: O estudo aborda que no Brasil é o cenário de posicionamentos conflitantes acerca dos efeitos jurídicos e do ativismo judicial, do qual tem sido alvo de polemica e conflitos especialmente de ordem social por estarmos em pandemia mundial. O objetivo geral do estudo é de compreender o sistema do ativismo judicial a partir de fundamentações teóricas em relação ao direito à Saúde em tempos de pandemia, demonstrando a partir da análise doutrinária e jurisprudencial que o Judiciário se torna hábil a garantir e efetivar o direito à saúde dos cidadãos. O presente estudo foi elaborado através de revisão de integrativa, exploratória com pesquisa qualitativa, com abordagem observacionais, através de aspectos relevantes acerca da pandemia. Conclui-se que ante a urgência a disseminação desenfreada do vírus, o processo legislativo torna-se ineficaz ante sua morosidade ainda que haja uma boa intenção por parte dos parlamentares em suprir as necessidades da população. Assim, com muitas demandas surgidas nessa época e carentes de uma resposta urgente, o Legislativo se encontra inviabilizado de dar a resposta efetiva e dentro de um prazo razoável.

Palavras chaves: Ativismo judicial efeitos jurídicos. Pandemia. Direito à saúde.

ABSTRACT: The study addresses that Brazil is the scene of conflicting positions about the legal effects and judicial activism, which has been the target of polemics and conflicts, especially of a social order, because we are in a global pandemic. The general objective of the study is to understand the system of judicial activism from theoretical foundations in relation to the right to Health in times of pandemic, demonstrating from the doctrinal and jurisprudential analysis that the Judiciary becomes able to guarantee and enforce the right to citizens' health. The present study was elaborated through an integrative, exploratory review with qualitative research, with an observational approach, through relevant aspects about the pandemic. It is concluded that given the urgency of the rampant dissemination of the virus, the legislative process becomes ineffective due to its slowness even though there is a good intention on the part of parliamentarians to meet the needs of the population. Thus, with many demands arising at that time and lacking an urgent response, the Legislature is unable to provide an effective response within a reasonable time.

Keywords: Judicial activism legal effects. Pandemic. Right to health.

${ }^{I}$ ICEC - Centro Cuiabano de Educação. Curso de Direito. Academica da disciplina TCC II, turma DIR Matutino.

${ }^{2}$ ICEC - Centro Cuiabano de Educação. Curso de Direito. Prof. Mestre, Orientador Email:alexandremurata76@gmail.com. 


\section{INTRODUÇÃO}

O país vive um momento atípico que tem sido marcado por restrições, isolamento, quarentena e em alguns lugares até o toque de recolher, e essa mudança sistemática na rotina dos brasileiros é reflexo de outros países pela propagação do vírus o Covid-ıq, que já matou cerca de 500 mil pessoas. Atualmente têm se buscado alternativas para evitar a propagação do vírus COVID-I9. A temática é relevante pois demonstrará situação envolvendo o coronavírus, e a sua atuação do judiciário na garantia da saúde.

O objetivo geral do estudo é de compreender o sistema do ativismo judicial a partir de fundamentações teóricas em relação ao direito à Saúde em tempos de pandemia, demonstrando a partir da análise doutrinária e jurisprudencial que o Judiciário se torna hábil a garantir e efetivar o direito à saúde dos cidadãos. Já os objetivos específicos propõem: Descrever o direito à social, o direito à saude, descrever a judicialização e o Covid-ı.

O presente artigo pretende expor a forma como o ativismo judicial, tão arraigado em nossos juízes, se apresentou neste cenário de crise, demonstrando que há uma cultura no Judiciário brasileiro de se fazer políticas públicas via decisões judiciais, contrariando o direito posto na sua acepção não positivista e deslegitimando os demais poderes estatais.

Observou-se que tal temática é importante pois buscou analisar e limitar como esta o Brasil nos tempos de Covid-ı, do qual teve a judicialização de temas inatos à política pública e a atividade legislativa que propiciou terreno para o ativismo judicial.

A questão norteadora do estudo incidiu na investigação da inercia legislativa acerca do ativismo judicial em tempos de pandemia, a fim de realizar as necessidades sociais concentradas na espera de regulamentação legislativa. Assim formulou-se a problemática que incidiu na investigação: A falta de protagonismo e de efetividade dos Poderes políticos causa a expansão da atividade jurisdicional que vem atuar numa conduta ativista garantidor de direitos e controlador de políticas públicas?

O presente estudo foi elaborado através de revisão de integrativa, exploratória com pesquisa qualitativa, com abordagem observacionais, através de aspectos relevantes acerca da pandemia. 


\section{DIREITO SOCIAL}

\subsection{Aspecto Geral}

Inicia-se o presente artigo abordando que a história dos direitos sociais surgiram, historicamente, "como criações do movimento socialista, que sempre colocou no pináculo da hierarquia de valores a igualdade de todos os grupo ou classes sociais, no acesso a condições de vida digna". Nota-se que em 1848 , em consequência do descontentamento dos trabalhadores com os excessos do capitalismo do Reinado de Luis Felipe de Orléans, e sob a influência do Manifesto Comunista de Marx e Engels, publicado no mesmo ano, uma nova Revolução estourou na França, visando a reinstalação da República, a Constituição Francesa de 1848 , foi à partir daí que se iniciou o processo de criação do que viria a ser o Estado do Bem-Estar Social no século XX, instituindo deveres sociais do Estado para com os trabalhadores e os necessitados em seu artigo 13:

A Constituição garante aos cidadãos a liberdade de trabalho e de indústria. A sociedade favorece e encoraja o desenvolvimento do trabalho ela fornece assistência às crianças abandonadas, aos doentes e idosos sem recursos e que não podem ser socorridos por suas famílias. (RAMAYANA, 2010, p.67).

Esclarece que a igreja também exerceu forte influência no reconhecimento dos direitos sociais e da necessidade da intervenção do Estado para a realização do bem comum e da justiça social. Nota-se que o movimento católico social representou uma mudança no pensamento da Igreja no que dizia respeito ao trabalho, pobreza e economia. E, tal, movimento teve início com a chamada doutrina social da Igreja, a partir da encíclica Rerum Novarum, editada pelo Papa Leão XIII, em I89I. Esta versava sobre as Obrigações e limites da intervenção do Estado, Obrigações dos operários e dos patrões, Dignidade do trabalho, caridade, equidade e justiça distributiva, ao mesmo tempo em que criticava o socialismo.

Ressalta-se que na mesma linha são as encíclicas Quadragésimo Anno, editada pelo Papa Pio XI, em 1931, dispondo sobre a restauração e aperfeiçoamento da ordem social; a Mater et Magistral, de 196I, editada pelo Papa João XXIII, dispondo sobre a evolução da questão social à luz da doutrina cristã e Pacem in Terris, editada em 1963, pelo Papa João XXIII, dispondo sobre a paz de todos os povos na base da verdade, justiça, caridade e liberdade. 
Deste modo, frente à influência dos movimentos sociais acima relatados, inicia-se no século XX, com a Constituição Mexicana de 1917 e a Constituição Alemã de 1919 o chamado constitucionalismo social, assim entendido como o movimento que, considerando uma das principais funções do Estado a realização da Justiça Social, propõe a inclusão de direitos trabalhistas e sociais fundamentais nos textos das Constituições dos países.

O título I da Constituição Mexicana de 1917 , em seu artigo $5^{\circ}$ que, atribuiu à liberdade de trabalho a qualidade de garantia individual, e o Título VI, em seu extenso artigo I23 regulamentou direitos trabalhistas, como a limitação da jornada de trabalho em 8 horas, a idade mínima para o trabalho, a proteção da maternidade, entre outros, e também o direito à previsión social.

\footnotetext{
A liberdade de todos só pode ser obtida pela ação do Estado. Mais ainda, que a liberdade é mera aparência se não precedida por uma igualização das oportunidades decorrentes de se garantirem a todos as condições mínimas de vida daí a intervenção do Estado nos domínios econômico e social. (RAMAYANA, 2010, p.69).
}

Assim, houve a concretização do Estado do Bem-Estar, Estado Social ou Estado Providencialista.

\subsection{Direito à Saúde}

O direito à saúde é um direito que é inerente a existência de todos os cidadãos, de caráter fundamental, sendo garantido em nossa Carta Magna, vejamos:

Art. $5^{\circ}$ - Todos são iguais perante a lei, sem distinção de qualquer natureza, garantindo-se aos brasileiros $e$ aos estrangeiros residentes no País a inviolabilidade do direito à vida, à liberdade, à igualdade, à segurança e à propriedade (BRASIL, I988).

Da mesma forma, ao tratar dos Direitos Sociais, a Constituição Federal, em seu Art.6o estabelece que: "São direitos sociais a educação, a saúde, o trabalho, a moradia, o lazer, a segurança, a previdência social, a proteção à maternidade e à infância, a assistência aos desamparados, na forma desta Constituição”. (BRASIL, 1988).

Art. 196. A saúde é direito de todos e dever do Estado, garantido mediante políticas sociais e econômicas que visem à redução do risco de doença e de outros agravos e ao acesso universal e igualitário às ações e serviços para sua promoção, proteção e recuperação. 
Art. 197 - São de relevância pública as ações e serviços de saúde, cabendo ao Poder Público dispor, nos termos da lei, sobre sua regulamentação, fiscalização e controle, devendo sua execução ser feita diretamente ou através de terceiros e, também, por pessoa física ou jurídica de direito privado (BRASIL, 1988).

Além de preceituar o SUS, a Constituição Federal, do enorme avanço ao apresentar em seu corpo normativo o Art. 199, o qual ensina:

Art. 199. A assistência à saúde é livre à iniciativa privada.

§ I $\mathrm{o}$ As instituições privadas poderão participar de forma complementar do sistema único de saúde, segundo diretrizes deste, mediante contrato de direito público ou convênio, tendo preferência as entidades filantrópicas e as sem fins lucrativos.

§ 2 - É vedada a destinação de recursos públicos para auxílios ou subvenções às instituições privadas com fins lucrativos.

$\S 3^{\circ} \mathrm{E}$ vedada a participação direta ou indireta de empresas ou capitais estrangeiros na assistência à saúde no País, salvo nos casos previstos em lei.

$\S 4^{\circ}$ A lei disporá sobre as condições e os requisitos que facilitem a remoção de órgãos, tecidos e substâncias humanas para fins de transplante, pesquisa e tratamento, bem como a coleta, processamento e transfusão de sangue e seus derivados, sendo vedado todo tipo de comercialização (BRASIL, 1988).

O amparo constitucional quanto à assistência à saúde pela iniciativa privada de

forma complementar ao SUS, foi o início da revolução normativa acerca do tema, tendo em vista que anteriormente não existiam normas reguladoras para a saúde suplementar.

\subsection{Judicialização}

A judicialização é um termo que tem sido empregado para significar que algumas questões políticas e sociais estão sendo decididas no âmbito do Judiciário, e não pelas instâncias políticas tradicionais: o Parlamento e o Poder Executivo, trata-se de uma tendência mundial, que, no Brasil, tem como causas preponderantes a redemocratização, que teve como ponto culminante a promulgação da atual Constituição, a constitucionalização abrangente, tornando constitucionais matérias que antes eram submetidas ao princípio da legalidade ou ao processo político majoritário, e o sistema misto de controle de constitucionalidade (BARROSO, 2019).

Segundo Silva (2018) a expansão do Poder judiciário é uma expressão largamente utilizada pela doutrina em âmbito nacional e internacional, cujo significado pode variar consideravelmente. Assim identifica-se apenas a adesão à ideia de ampliação da função 
jurisdicional para áreas que tradicionalmente não eram de sua competência. A expressão ativismo judicial foi utilizada pela primeira vez pelo jornalista norte-americano Arthur Schlesinger incumbido de fazer a radiografia da Suprema Corte dos Estados Unidos com ênfase de como os juízes se portaram diante da política do New Deal. Ao mapear as decisões, o mesmo percebeu que havia duas espécies de juízes: os que acreditavam que se valendo de princípios, podiam avançar na interpretação da Constituição para garantir direitos; e os que consideravam não ter competência para isso e deviam apenas dizer o que era a lei de acordo com a norma escrita, assim, pode se dizer que uns são ativistas e outros praticam a jurisprudência defensiva ou de autocontenção.

Já Teixeira (2012) define o termo ativismo judicial se consagrou e, atualmente ocupa grande espaço no debate institucional. No Brasil, esta idéia está relacionada a uma participação ampla do Judiciário na efetivação dos direitos fundamentais. Assim, o Processo Civil Brasileiro deixa de ser visto apenas como um conjunto de procedimento formal para ser interpretado como um instrumento de entrega eficaz da jurisdição em atenção aos princípios constitucionais da celeridade e da duração razoável do processo, após a reforma dada pela $\mathrm{EC} \mathrm{n}^{-}$45/2004. Entende-se o termo ativismo judicial como a conduta proativa do Poder Judiciário em prol de uma justiça mais eficaz.

Deste modo, o Processo Civil Brasileiro deixa de ser visto apenas como um conjunto de procedimento formal para ser interpretado como um instrumento de entrega eficaz da jurisdição em atenção aos princípios constitucionais da celeridade e da duração razoável do processo, após a reforma dada pela EC no 45/2004. O ativismo judicial, assim, entende-se como a conduta proativa do Poder Judiciário em prol de uma justiça mais eficaz.

[...] Por ativismo judicial deve-se entender o exercício da função jurisdicional para além dos limites impostos pelo próprio ordenamento que incumbe institucionalmente ao poder judiciário, resolvendo litígios de feições subjetiva. Há uma sinalização claramente negativa no tocante às práticas ativistas, por importarem na desnaturação da atividade típica do poder judiciário, em detrimento dos demais poderes (RAMOS, $2012 \mathrm{p}$. 7I).

O ativismo judicial está anexo a uma participação mais ampla e intensa do Judiciário na concretização dos valores e fins constitucionais, com maior intervenção no espaço de atuação dos Poderes Legislativo e Executivo. Logo, tudo decorre do exercício da 
jurisdição constitucional, que, não obstante tensões institucionais, no Estado Democrático de Direito, transforma-se na garantia da eficácia dos direitos fundamentais sociais e da própria democracia (RAMOS, 2012).

Define-se o ativismo judicial sendo uma expressão na sociedade contemporânea, do qual se associa a outras expressões sociais, caracteriza-se como ativismo de cidadania ou ativismo dos direitos humanos, onde o juiz exerce uma função em que a concretização dos direitos fundamentais é rotina e precisa estar consciente de que dele depende a etapa mais séria dessa doutrina: a sua efetiva implementação.

\subsection{A Pandemia Mundial}

Com efeito, a crise enfrentada em razão da pandemia instituiu um estado de calamidade pública no país e os esforços imprimidos pelos poderes públicos no combate ao vírus, como o isolamento social, possuem características do estado de sítio e de defesa não antes vivenciados pela sociedade e pelos governantes.

A crise vai muito além da questão sanitária perpassando as áreas da economia, educação, liberdades e garantias individuais, entre outras, requerendo uma alteração comportamental de todos os envolvidos. Há necessidade de mudança nos hábitos sociais (relativos à higiene, festividades e turismo) e também no que tange ao comportamento das autoridades públicas que, no presente momento, devem velar mais do que nunca, pelo princípio da transparência e da publicidade frente aos administrados.

Essa mudança comportamental gera reflexos diretos na economia, principalmente as medidas de distanciamento social e os decretos de lock down, que acabam por gerar queda no comércio, perda de renda, desemprego e um grande receio populacional, os quais irão depender de políticas públicas eficazes a fim de contrabalancear as perdas do período.

\subsection{COVID-19}

O primeiro caso de coronavírus confirmado no Brasil foi identificado no final de fevereiro do ano passado e de lá para cá, já são mais de 350 mil óbitos. A Organização 
Mundial de Saúde (OMS, 2020) já classificou a situação da doença como uma pandemia, isso significa que a doença infecciosa alcançou nível de propagação mundial. ${ }^{3} \mathrm{O}$ sequenciamento do vírus no Brasil aconteceu em tempo recorde, apenas $48 \mathrm{~h}$, no resto do mundo, o tempo médio para o procedimento ser realizado é de 15 dias.

Pode se dizer que segundo esses marcadores epidemiológicos, a epidemia tende a produzir uma concentração demasiada de casos num curto intervalo de tempo. Na Itália, China e Espanha, o crescimento do número de casos em semanas foi importante a ponto de colapsar os sistemas de saúde locais. Observa-se que atualmente, houve uma redução importante no número de casos na China, até que o país atingiu um registro nulo de casos por transmissão local o que exclui, os indivíduos que vieram de outros países com a doença.

Com a pandemia pode-se verificar que na área da saúde passou por diversas mudanças, e é de suma importância a atuação bem como a humanização tema este em alta por ser preconizado e preocupado na oferta do cuidado integral ao paciente, analisando-o em sua totalidade, dentro deste contexto.

O país registrou I.824 mortes pela Covid-ı nas últimas 24 horas e totalizou neste domingo (II/o7) 553.293 óbitos desde o início da pandemia. Com isso, a média móvel de mortes no Brasil nos últimos 7 dias chegou a 3.109. É a segunda maior média móvel de mortes já registrada, inferior apenas ao número de Io de abril (3.119). Em casos confirmados, desde o começo da pandemia 13.482.543 brasileiros já tiveram ou têm o novo coronavírus, com 38.859 desses confirmados no último dia. A média móvel nos últimos 7 dias foi de 71.283 novos diagnósticos por dia. Quatorze estados e o Distrito Federal estão com alta nas mortes: AP, AM, CE, DF, ES, GO, MA, MS, MG, PR, PE, PI, RJ, RR e SP. Afirma-se que todas as competentes medidas que podem proteger e que estão previstas no protocolo de manejo clínico do coronavírus, são acatadas à biossegurança.

É importante entender que se trata uma pandemia e suas consequências para as relações jurídicas preexistentes, nesse contexto é imprescindível a sua contextualização no

3 Dados extraídos de: https: <//brasil.elpais.com/brasil/2020-04-o6/ao-vivo-ultimas-noticias-sobre-ocoronavirus-no-brasil-e-no-mundo.html> Acesso 02 de Ago de 2021. 


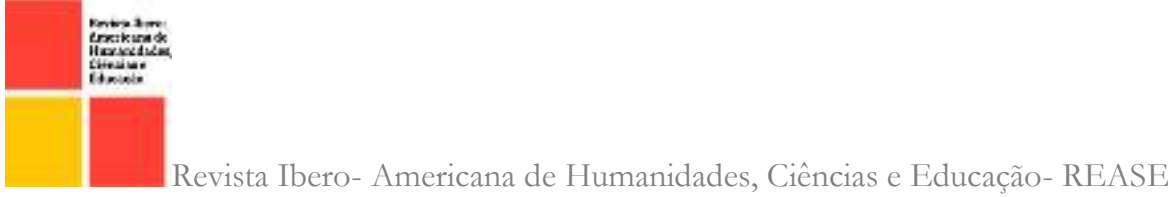

presente trabalho, no qual ira demonstras seus principais aspectos. Assim, as divergências existentes tanto doutrinaria quanto jurisprudencial deve-se apresentar os conceitos existentes sobre o significado de pandemia.

Segundo a OMS (Organização Mundial da Saúde) uma pandemia é a disseminação mundial de uma nova doença, o termo é utilizado quando uma epidemia grande surto que afeta uma região se espalha por diferentes continentes com transmissão sustentada de pessoa para pessoa.

\subsection{Ativismo Judicial na Pandemia}

Vivemos dias de urgência na saúde situação, o processo legislativo não se mostra eficaz devido a sua morosidade, e mesmo vendo o interesse do Poder Legislativo, nos trâmites pelos quais devem seguir a criação das leis, não há como sanar as necessidades sociais na crise dentro de um tempo razoável por meio de edição de atos normativos. Assim, a atuação do Poder Executivo, em todos os níveis têm sido ineficiente, principalmente, o federal que demonstra vivenciar uma crise orgânica, mantendo-se o atual Presidente da República apartado das instituições que compõem nosso Estado Democrático de Direito.

A pandemia do novo coronavírus que atingiu o mundo nos últimos meses, principalmente o Brasil, colocou em evidência que os poderes republicanos Legislativo e Executivo foram ineficientes e morosos diante da rápida contaminação do vírus em se tratando de medidas de contenção. Com a falta de liderança e a expansão do vírus, o Poder Judiciário dispôs de protagonismo com decisões acentuadas e certeiras que, vindo atuar em uma conduta ativista e garantindo a defesa dos direitos fundamentais. O Judiciário acaba assumindo o poder político de legislar e impelir medidas ao Executivo diante da inércia no âmbito federal.

No atual cenário, em que o Legislativo atual vê se que parte de sua eficiência deixa que o Executivo ser efetivo, e o Poder Judiciário passa a ser o grande garantidor de direitos e controlador de políticas públicas, numa conduta ativista e emancipatória diante daqueles que buscam a tutela estatal. Assim, o ativismo judicial vem a ser uma maior atuação do 
Poder Judiciário com ingerência aos demais Poderes, visando a realização de valores e garantias previstas constitucionalmente.

É assim que o ativismo se manifesta de várias formas, pela aplicação direta da Constituição Federal, quando do exercício do controle de constitucionalidade dos atos normativos em sentido amplo e, ainda, através do controle de políticas públicas, ao impor ou determinar abstenções de condutas por parte do Poder Público. Já no tocante da legitimidade da atuação ativista do Poder Judiciário, temos que, por se tratar de um período excepcional, de crise, a legitimidade das decisões judiciais ativistas devem ser reconhecidas sob pena de que situações ocorridas nesse período deixem de receber a tutela estatal necessária e devida. Outrossim, as decisões ativistas desse período também serão legítimas se consideradas sob o aspecto da contingência.

Dentro disso, a hipótese a ser analisada na presente pesquisa é da expansão da judicialização da política e a politização das decisões judiciais caracterizando o ativismo judicial devido a falta de protagonismo e efetividade do Poder Legislativo e Executivo ante a crise causada pelo COVID-ıg, fato que legitima a ação ativista do Poder Judiciário.

A crise estabelecida mundialmente provocada pela disseminação do vírus SARSCoV-2, gerador do COVID-ı9, e que, inevitavelmente, atingiu o Brasil a partir de março de 2020 vem causando inúmeros problemas. De fato, a pandemia pelo COVID-i9 não causa apenas uma crise de saúde pública, mas reflete-se também e diretamente na economia e nos padrões comportamentais de toda a sociedade, requerendo uma atitude proativa de todos e, das autoridades públicas.

Reconhecido o estado pandêmico o primeiro passo foi a determinação de alteração no comportamento da rotina social, com a imposição do isolamento e distanciamento social, vedação de realização de grandes eventos, festas e encontros sociais, fechamento de comércios ligados a área de turismo, tais como, hotéis e pousadas. Ainda, a recomendação do uso de máscaras, modos e meios de higienização e formas de interação social.

O caos social, o mais grave dos resultados negativos, repercute na economia, refletindo-se na ausência de ajuda aos mais vulneráveis, fazendo com que haja um aumento no índice de fome, desemprego, falta de confiança do povo, morte. Em que pese o governo federal ter aprovado o auxílio emergencial verifica-se que sua aplicabilidade não 
tem a eficácia esperada, uma vez que ineficiente para suprir todas as necessidades básicas do cidadão, além das fraudes já constatadas.

Decisão: O Tribunal, por unanimidade, referendou a medida cautelar concedida, para determinar que: (a) o Ministério da Saúde mantenha, em sua integralidade, a divulgação diária dos dados epidemiológicos relativos à pandemia (COVID-I9), inclusive no sítio do Ministério da Saúde e com os números acumulados de ocorrências, exatamente conforme realizado até o último dia 04 de junho de 2020; e (b) o Governo do Distrito Federal se abstenha de utilizar nova metodologia de contabilidade dos casos e óbitos decorrentes da pandemia da COVID-I9, retomando, imediatamente, a divulgação dos dados na forma como veiculada até o dia 18 de agosto de 2020, nos termos do voto do Relator. Falou, pelos requerentes, o Dr. Levi Borges de Oliveira Veríssimo. Plenário, Sessão Virtual de 13.11.2020 a 20.11.2020.

Decisão: O Tribunal, por unanimidade, julgou parcialmente procedente a arguição de descumprimento de preceito fundamental, para determinar que: (a) o Ministério da Saúde mantenha, em sua integralidade, a divulgação diária dos dados epidemiológicos relativos à pandemia (COVID-19), inclusive no sítio do Ministério da Saúde e com os números acumulados de ocorrências, exatamente conforme realizado até o dia 4 de junho de 2020; (b) o Governo do Distrito Federal se abstenha de utilizar nova metodologia de contabilidade dos casos e óbitos decorrentes da pandemia de COVID-ı, mantendo a divulgação dos dados na forma como veiculada até o dia 18 de agosto de 2020, nos termos do voto do Relator. Falaram: pela requerente Rede Sustentabilidade, a Dra. Kamila Rodrigues Rosenda; e, pelo amicus curiae Open Knowledge Brasil - OKBR, a Dra. Bianca dos Santos Waks. Plenário, Sessão Virtual de 5.3.2021 a 12.3.2021.

Em 8.6.2020 "(...) Diante do exposto, CONCEDO PARCIALMENTE A MEDIDA CAUTELAR na presente arguição de descumprimento de preceito fundamental, ad referendum do Plenário desta SUPREMA CORTE, com base no art. 2i, V, do RISTF, para DETERMINAR AO MINISTRO DA SAÚDE QUE MANTENHA, EM SUA INTEGRALIDADE, A DIVULGAÇÃO DIÁRIA DOS DADOS EPIDEMIOLÓGICOS RELATIVOS À PANDEMIA (COVID-19), INCLUSIVE NO SÍTIO DO MINISTÉRIO DA SAÚdE E COM OS NÚMEROS ACUMULADOS DE OCORRÊNCIAS, EXATAMENTE CONFORME REALIZADO ATÉ O ÚLTIMO DIA o4 DE JUNHO. Em virtude da urgência, intime-se, inclusive por meio de Whatsapp do Advogado-Geral da União, a União para o cumprimento da decisão e para prestar as informações que entender necessárias, em 48 (quarenta e oito) horas. Após o transcurso desse prazo, os autos deverão ser imediatamente conclusos para análise dos demais pedidos liminares e envio imediato ao Plenário da CORTE. Publiquese."

O governo federal nega-se em fazer uso da ciência na tomada de decisões, indo de encontro com toda a literatura médica e epidemiológica a respeito do caso e, inclusive, as recomendações da OMS, o que faz com que governos estaduais e municipais divirjam a respeito e passem a implementar estratégias próprias. 
O ministro Alexandre de Moraes reiterou seus fundamentos das decisões anteriores, pela publicidade das informações. Para o relator, a abrupta interrupção da coleta e divulgação dos dados caracteriza ofensa a preceitos fundamentais da Constituição Federal, nomeadamente o acesso à informação, os princípios da publicidade/transparência da Administração Pública e o direito à saúde, o ministro entendeu pela necessidade, em juízo de mérito, da manutenção da divulgação integral de todos os dados epidemiológicos que o ministério da Saúde realizou e o Governo do Distrito Federal, até I8 de agosto do mesmo ano, sob pena de dano irreparável decorrente do descumprimento dos princípios constitucionais da publicidade e transparência e do dever constitucional de executar as ações de vigilância sanitária e epidemiológica em defesa da vida e da saúde de todos os brasileiros, especialmente, nos termos dos artigos 196, 197 e 200 da Constituição Federal.

\section{CONSIDERAÇÕES FINAIS}

Através da metodologia neste estudo, verificou-se que não há outro meio de se garantir de forma efetiva os direitos pleiteados bem como, controlar e aplicar as políticas públicas cabíveis às situações de crise sem a postura intervencionista e ativista do Judiciário. O Poder Judiciário, não atua com ingerência aos demais Poderes, levando-se em consideração a morosidade legislativa e o atual papel figurativo do Executivo. Dessa forma, verifica-se claramente a ineficiência do Poder Executivo na elaboração de políticas públicas eficazes na contenção de riscos e prejuízos aos cidadãos, bem como, no fazimento de melhorias e prestação de auxílios aos mais vulneráveis.

Conclui-se que ante a urgência a disseminação desenfreada do vírus, o processo legislativo torna-se ineficaz ante sua morosidade ainda que haja uma boa intenção por parte dos parlamentares em suprir as necessidades da população. Assim, com muitas demandas surgidas nessa época e carentes de uma resposta urgente, o Legislativo se encontra inviabilizado de dar a resposta efetiva e dentro de um prazo razoável. 


\section{REFERENCIAS}

BARROSO, Luís Roberto. O controle de constitucionalidade no direito brasileiro: exposição sistemática da doutrina e análise crítica da jurisprudência. - $4^{\underline{a}}$ ed. rev. e atual. São Paulo: Saraiva, 2009.

TEIXEIRA, Anderson Vichinkeski. Ativismo judicial: nos limites entre racionalidade jurídica e decisão política. Rev. direito GV [online]. 2012, vol.8, n.I, pp. 037-057. ISSN I8082432.

RAMOS, Elival da Silva. Ativismo Judicial: Parâmentros dogmáticos. 2. Ed. São Paulo: Saraiva, 2012.

SILVA, Virgílio Afonso da. A constitucionalização do direito - os direitos fundamentais nas relações entre particulares. São Paulo: Malheiros, 2008.

NALINI, José Renato. "Protagonismo ético judicial e perspectivas do Judiciário no século XXI". Revista dos Tribunais, São Paulo, RT, ano 98, vol. 889, nov. 2009.

STRECK, Lenio Luiz. "Uma abordagem hermenêutica acerca do triângulo dialético de Canotilho ou de como ainda é válida a tese da Constituição dirigente (adequada a países de modernidade tardia)". Direitos fundamentais e Estado Constitucional: estudos em homenagem a J. J. Gomes Canotilho. Coordenação de George Salomão Leite e Ingo Wolfgang Sarlet. São Paulo: RT, 2009. 